\title{
Novel [2]Pseudorotaxanes Containing Cucurbituril as a Molecular Bead: Unexpected Formation of a Kinetic Product Which Spontaneously Converts into a Thermodynamic Product by Translocation of the Bead ${ }^{\dagger}$
}

\author{
Jae Wook Lee, SooWhan Choi, Young Ho Ko, Soo-Young Kim, and Kimoon Kim \\ National ('reative Research Initiative ('enter for Simart Supramolecules and Department of ( hemistrv, Dinision of tolecular \\ and life Siciences, Pohang Iniversity of Sicience and Technologv, Sian 31 Hyojadong, Pohang 790-784, Korea \\ Received March 29,2002
}

Key Words : Cucurbituril. (Pscudo)rolasanes. Sclf-assembly. Kinetic product. Slipping meclanisism

The construction of nanometer-scale devices such as molecular machines and switches from molecular components is of much interest in recent years.' Mechanically interlocked molecules such as rotaxanes and catemanes have great potential as such molecular devices because the relative positions of their components can be induced to change by external stimuli. ${ }^{2}$ For example, in a [2]rotaxane. which is composed of a ring threaded on a linear chain terminated by bulky stoppers. the translocation of the ring along the linear component can be achieved by external chemical. electrochemical. or photochemical stimuli. In appropriately designed systems. such mechanical movements occur between two different well-defined states so that they behave as molecular machines or switches that are potentially usefil in molecular-scale information storage and processing as well as sensor.

Cucurbituril (CB[6]) is a macrocycle comprising six glycoluril units with a hydrophobic cavity that is accessible through two identical carbony l-fringed portals. ${ }^{3.4}$ In the past several years. we have synthesized novel mechanically interlocked molecules such as rotaxanes, poly rotaxanes, and molecular necklaces by taking advantage of the strong tendency of $\mathrm{CB}[6]$ to form stable host-giest complexes with diaminoalkane derivatives. ${ }^{5}$ For example, $N, N^{\prime}$-bis (4-pyridylmethyl)-1.t-diaminobutane dilydrochloride and $\mathrm{CB}[\mathrm{G}]$ readily form a pseudorotaxane which then reacts with a metal ion or complex to form a polyrotaxane or a molecular necklace. More recently; our efforts have been focused on molecular machines and switches based on [2|rotaxanes. ${ }^{\circ}$ To realize molecular device. however. such molecular machines or switches need to be organized at an interface or on the surface of a solid to behave colherently. ${ }^{7}$ Therefore. we initiated our efforts to anchor rotaxane-based molecular switches on a solid surface. As a preliminary work we designed and synthesized a (pseudo)rotaxane that can be attached on a surface by covalent bond. Here we report the synthesis of a novel [2|rotaxane by threading a molecular "bead" with a diaminoalkane-based "string" containing a

\footnotetext{
I) Jedicated to the memory of l'rofessor Sang C'hul Shim, an outstanding scientist, teacher and administrator of our age

"Corresponding Author. F-mail: kkimià postech ac kr: Fax: +82$54-279-8129$
}

pyridinemethyl teminal and an iminodicarboxylic acid terminal. Interestingly. the threading process first produces a kinetic product which then converts into a thermodynamic product by translocation of the molecular "bead" along the "string".

\section{Experimental Section}

General procedure for the preparation of tertiary amine 2. To a solution of primary amine $1(4 \mathrm{mmol})$ and disopropylethylamine $(8.1 \mathrm{mmol})$ in $\mathrm{CH}_{3} \mathrm{CN}(40 \mathrm{~mL})$ in an ice bath was added methyl bromoacetate $(8.8 \mathrm{mmol})$ and then the resulting solution was stirred for $20 \mathrm{~h}$ at room temperature. After the solvent was removed by evaporation and the residue was dissolved in dichloromethane $(80 \mathrm{~mL})$. The resulting solution was washed with aqueous $\mathrm{NaHCO}_{3}$ solution. dried, and evaporated to give a crude product that was further purified by column chromatography using EtOAc/n-hexane as an eluent.

2a: $97 \%$ yield: ${ }^{~} \mathrm{H}$ NMR $\left(\mathrm{CDCl}_{3}\right) \delta 1.35$ (m. $\left.2 \mathrm{H}\right), 1.42$ (m. $2 \mathrm{H}) .1 .57$ (nt. 2H). 2.67 (t. $J=7.1 \mathrm{~Hz}, 2 \mathrm{H}) .3 .23$ (t. $J=6.9$ Hz. $2 \mathrm{H}$ ). 3.51 (s. $4 \mathrm{H}), 3.67$ (s. $6 \mathrm{H}):{ }^{13} \mathrm{C} \mathrm{NMR}\left(\mathrm{CDCl}_{3}\right) \delta$ 24.6. 27.8. 29.0. 51.7. 51.9. 54.5. 55.2. 172.0. MS (EI): $m z$ $273\left[\mathrm{M}^{+}\right]$.

2b: $98 \%$ yield: ' $\mathrm{H}$ NMR $\left(\mathrm{CDCl}_{3}\right) \delta 1.35(\mathrm{~m} .4 \mathrm{H}) .1 .49$ (m. $2 \mathrm{H}) .1 .60$ (nI. $2 \mathrm{H}) .2 .70$ (t. $J=7.3 \mathrm{~Hz} .2 \mathrm{H}$ ). 3.26 (t. $J=6.9$ Hz. $2 \mathrm{H}$ ). 3.55 (s. $4 \mathrm{H}), 3.71$ (s. $6 \mathrm{H}):{ }^{13} \mathrm{C}$ NMR $\left(\mathrm{CDCl}_{3}\right) \delta$ 26.9.27.0. 28.1. 29.1. 51.7. 51.9. 54.6. 55.2. 172.1: MS (EI): $m=287\left[\mathrm{M}^{+}\right]$.

General procedure for the preparation of (4-pyridylmethyl)aminoalkyliminodiacetic acid 3 . A solution of 2 (2 mmol) in $\mathrm{MeOH}(20 \mathrm{~mL})$ was stirred for $15 \mathrm{~h}$ at roon temperature in the presence of $\mathrm{Pd} / \mathrm{C}$ under $\mathrm{H}_{\imath}$ atmosphere. The resulting solution was filtered through Celite and concentrated to give an anine internediate which was then reacted in situ with 4-pyridylaldelyde (2 nunol) in $\mathrm{MeOH}$ $(15 \mathrm{~mL})$ in the presence of $4 \mathrm{~A}$ nolecular sieve for $20 \mathrm{~h}$. To the resulting solution was treated with $\mathrm{NaBH}_{4}$ and then stirred for $10 \mathrm{~h}$. The reaction mixture was concentrated and dissolved with $\mathrm{CH}_{2} \mathrm{Cl}_{2}$. After wasling with aqueous $\mathrm{NaHCO}_{3}$ solution, the organic phase was dried and evaporated to afford a crude product. The crude product was dissolved in a mixture of THF $(15 \mathrm{~mL})$ and $\mathrm{H}_{2} \mathrm{O}(15 \mathrm{~mL})$ in the presence of 
$\mathrm{NaHCO}_{3}(2 \mathrm{mmol})$. To the resulting solution was added $\mathrm{Cb} / \mathrm{Cl}$ at $5^{\circ} \mathrm{C}$ and the mixlure was stirred for $2 \mathrm{~h}$ at the same temperature and $3 \mathrm{~h}$ at room temperature before E1OAc (60) $\mathrm{mL}$ ) was added. The resulting mixture was washed with aqueous $\mathrm{NaHCO}_{3}$ solution and the organic phase was scparated. dricd. and concentrated to give $\mathrm{Cb} \%$-protected aminodiester which was further purified by column chromatography. Finally a solution of $\mathrm{Cb} z$-protecied aminodicsicr ( $\mathrm{l}$ mmol) in $\mathrm{HBr}-\mathrm{H}_{2} \mathrm{O}(10 \mathrm{~mL})$ was stirred for $5 \mathrm{~h}$ at $80^{\circ} \mathrm{C}$ before the solution was concentrated by evaporation. Addition of E1OAc to the solution produced a solid which was filtered washed with ether extensively to afford 3 .

3a: $40 \%$ yicld: ${ }^{1} \mathrm{H}$ NMR $\left(\mathrm{D}_{2} \mathrm{O}\right) \delta$ 1.48 (m, 2H), $1.82(\mathrm{~m}$. $4 \mathrm{H}) .3 .24(1 . J=7.7 \mathrm{H} / 2 \mathrm{H}) .3 .38(1 . J=8.0 \mathrm{H} \approx 2 \mathrm{H}) .4 .17$ (s. 4H). 4.63 (s. 2H). $8.19(\mathrm{~d} . J=6.5 \mathrm{H} \% 2 \mathrm{H}) .8 .90(\mathrm{~d} . J=$ $6.6 \mathrm{~Hz} .2 \mathrm{H}):{ }^{13} \mathrm{C}$ NMR $(\mathrm{D}=\mathrm{O}) \delta 23,0.23,4,25,3.48 .3,49.6$. 55.6. 56.7. 127.8. 142.3. 152.0. 169.1: MS (EI): $\left.m z 309\right|^{\prime} \mathrm{M}^{\prime}$ $-3 \mathrm{HBr}] .471$ [M $-\mathrm{HBr}]$.

3b: $38 \%$ yicld: ${ }^{1} \mathrm{H}$ NMR (D-O) $\delta 1.42(\mathrm{~m} .4 \mathrm{H}) .1,76(\mathrm{~m}$. $4 \mathrm{H}) .3 .21(\mathrm{l} . J=7.8 \mathrm{H} \% 2 \mathrm{H}) .3 .35(1 . J=8.1 \mathrm{H} \% 2 \mathrm{H}) .4 .17$ (s. $4 \mathrm{H}) .4 .60)($ s. $2 \mathrm{H}) .8 .17(\mathrm{~d} . J=6.6 \mathrm{H} \% 2 \mathrm{H}) .8 .88(\mathrm{~d} . J=$ $6.8 \mathrm{H} \% 2 \mathrm{H}){ }^{13} \mathrm{C}$ NMR $(\mathrm{D}, \mathrm{O}) \delta 23,5,25,4,25,5,25,6,48,6$. 49.6. 55.3. 57.0. 127.8. 142.4. 152.0. 168.9: MS (EI): $m z$ 323 [M $-3 \mathrm{HBr}$ ]

General procedure for [2]pseudorotaxane 4 . To a solution of $3(0.3 \mathrm{mmol})$ in $\mathrm{H}_{2} \mathrm{O}(30 \mathrm{~mL})$ was addcd $\mathrm{CB}[6](0.4$ mmol) in small portions and the mixture was stirred lor $\sim 20$ min at room temperature. Excess $\mathrm{CB}[6]$ was liltered out to provide a clear solution which was concentrated to I $\mathrm{mL}$ by evaporation. Addition of $\mathrm{E} 1 \mathrm{OH}(30 \mathrm{~mL})$ to the solution produced a precipitate which was filtered to afford 4 quantitatively.

4a: ${ }^{1} \mathrm{H}$ NMR (D, O) $\delta 1.86(\mathrm{~m} .2 \mathrm{H}) .1 .98(\mathrm{~m} .2 \mathrm{H}) .2 .2 \mathrm{l}(\mathrm{m}$. $2 \mathrm{H}) .3 .48(\mathrm{~m} .2 \mathrm{H}) .3 .59(\mathrm{t} . J=7.1 \mathrm{H} \% .2 \mathrm{H}) .4 .07$ (s. $4 \mathrm{H}) .4 .34$ (d. $J=16.0 \mathrm{H} \% 6 \mathrm{H}), 4.40(\mathrm{~d} . J=19.1 \mathrm{H} \% 6 \mathrm{H}) .4 .72(\mathrm{~s} .2 \mathrm{H})$. $5.60(\mathrm{~s} .12 \mathrm{H}) .5 .72(\mathrm{~d} . J=6.7 \mathrm{H} \% 6 \mathrm{H}) .5 .77(\mathrm{~d} . J=6.8 \mathrm{H} \%$ $6 \mathrm{H}) .7 .0](\mathrm{d} . J=6.6 \mathrm{H} / 2 \mathrm{H}) .8 .01(\mathrm{~d} . J=6.8 \mathrm{H} / .2 \mathrm{H})$ : ESIMS: $m=310.3([\mathrm{M}-\mathrm{CB}+\mathrm{H}]) .653 .8\left([\mathrm{M}+2 \mathrm{H}]^{2-1}\right)$ : Elcmental analysis (\%) calcd for $\mathrm{C}_{51} \mathrm{H}_{62} \mathrm{Br}_{3} \mathrm{~N}_{27} \mathrm{O}_{16} 7 \mathrm{H}_{2} \mathrm{O}: \mathrm{C} 36.57 . \mathrm{H}$ 4.57. N 22.58: found: C 36.55 . H 4.67. N 22.94 .

th: ${ }^{1} \mathrm{H}$ NMR (D $\left.2 \mathrm{O}\right) \delta 1.60(\mathrm{~m} .2 \mathrm{H}) .1 .77(\mathrm{~m} .2 \mathrm{H}) .1 .90(\mathrm{~m}$. $2 \mathrm{H}) .2 .17(\mathrm{~m} .2 \mathrm{H}) .3 .43(\mathrm{~m} .2 \mathrm{H}) .3 .56(\mathrm{t} . J=7.4 \mathrm{~Hz} .2 \mathrm{H})$. $4.04(\mathrm{~s} .4 \mathrm{H}), 4.34(\mathrm{~d} . J=16.0 \mathrm{~Hz} .6 \mathrm{H}), 4.40(\mathrm{~d} . J=19.8 \mathrm{~Hz}$. $6 \mathrm{H}) .4 .72$ (s. $2 \mathrm{H}$ ). 5.60 (s. 12H). 5.73 (distorted d. $6 \mathrm{H}$ ). 5.78 (distorted d. 6H). 7.02 (d. $J=6.5 \mathrm{~Hz} .2 \mathrm{H}$ ). 8.07 (d. $J=6.7$ Hz, 2H): ESI-MS: $m z 660.8\left([\mathrm{M}+2 \mathrm{H})^{--}\right) .671 .8([\mathrm{M}+\mathrm{H}+$ $\left.\mathrm{Na}]^{--}\right) \cdot 680.8\left(\left[\mathrm{M}+\mathrm{H}+\mathrm{Na}+\mathrm{H}_{2} \mathrm{O}^{2+}\right) \cdot 1037.3([\mathrm{CB}+\mathrm{Na}+\right.$ $\left.\mathrm{H}_{2} \mathrm{Ol}^{-}\right) .1320 .3\left(\left[\mathrm{M}+\mathrm{H}^{-}\right)\right.$: Elemental analysis $(\%)$ calcd for $\mathrm{C}_{32} \mathrm{H}_{6}+\mathrm{Br}_{3} \mathrm{~N}_{27} \mathrm{O}_{16} \mathrm{H}_{2} \mathrm{O}: \mathrm{C} 39.50 . \mathrm{H} 4.21, \mathrm{~N} 23.92$; found: $\mathrm{C}$ 39.22 . H 4.55, N 23.61 .

Formation of [2|pseudorotaxane 5 . A solution of 4 in $\mathrm{H}_{2} \mathrm{O}$ was stirred for several days at room temperature or a few minutes at $60-70{ }^{\circ} \mathrm{C}$. The resulting solution was evaporated to dryness to afford $\mathbf{5}$ quantitatively:

5a: ${ }^{1} \mathrm{H}$ NMR (D_O) $\delta 0.41(\mathrm{~m}, 2 \mathrm{H}) .0 .79(\mathrm{~m}, 2 \mathrm{H}) .1 .03(\mathrm{~m}$. $2 \mathrm{H}$ ). 2.53 (t. $J=9.0 \mathrm{~Hz}, 2 \mathrm{H}$ ) .3 .53 (t. $J=8.1 \mathrm{~Hz} .2 \mathrm{H}$ ) .4 .39 (d. $J=14.3 \mathrm{~Hz} .6 \mathrm{H}) .4 .44(\mathrm{~d} . J=14.4 \mathrm{~Hz}, 6 \mathrm{H}) .4 .78(\mathrm{~s} .4 \mathrm{H})$. 4.83 (s. $2 \mathrm{H}$ ). 5.68 (s. $12 \mathrm{H}$ ). 5.78 (d. $J=15.6 \mathrm{~Hz} .6 \mathrm{H}) .5 .87$ $(\mathrm{d} J=15.5 \mathrm{H} / .6 \mathrm{H}) .8 .59(\mathrm{~d} J=6.0 \mathrm{H} \% 2 \mathrm{H}) .9 .01(\mathrm{~d} . J=$ $6.2 \mathrm{H} / 2 \mathrm{H})$ : ESI-MS: $m=653.8\left([\mathrm{M}+2 \mathrm{H}]^{2}\right)$ : Elcmental analy sis (\%) calcd for $\mathrm{C}_{51} \mathrm{H}_{62} \mathrm{Br}_{3} \mathrm{~N}_{27} \mathrm{O}_{16 \mathrm{i}}: \mathrm{C}$ 39.55. H 4.03. N 24.42: found: $\mathrm{C} 39.33$. $\mathrm{H} \mathrm{4.47.} \mathrm{N} 24.72$.

sb: ${ }^{1} \mathrm{H}$ NMR $\left(\mathrm{D}_{2} \mathrm{O}\right) \delta 0.45(\mathrm{~m}, 4 \mathrm{H}), 0.76(\mathrm{~m}, 2 \mathrm{H}), 1.34(\mathrm{~m}$. $2 \mathrm{H}) .2 .85(\mathrm{t} . J=9.2 \mathrm{H} \% 2 \mathrm{H}) .3 .49(\mathrm{t} . J=7.8 \mathrm{H} / 2 \mathrm{H}) .4 .33$ (d. $J=14.6 \mathrm{H} \% 6 \mathrm{H}), 4.38(\mathrm{~d} . J=14.9 \mathrm{H} / 6 \mathrm{H}), 4.50(\mathrm{~s} .2 \mathrm{H})$. 4.62 (s. $2 \mathrm{H}$ ). 4.82 (s. $2 \mathrm{H}) .5 .6 \mathrm{l}$ (s. $12 \mathrm{H}) .5 .76(\mathrm{~d} . J=15.6 \mathrm{H} \%$ $6 \mathrm{H}) .5 .83(\mathrm{~d} . J=15.5 \mathrm{H} \% 6 \mathrm{H}) .8 .50(\mathrm{~d} . J=6.7 \mathrm{H} \% 2 \mathrm{H}) .8 .96$ (d. $J=6.7 \mathrm{H} \% 2 \mathrm{H}):$ ESl-MS: $m=660.8\left([\mathrm{M}+2 \mathrm{H}]^{21}\right)$ : Elemental analy sis (\%) calcd for $\mathrm{C}_{52} \mathrm{H}_{64} \mathrm{Br}_{3} \mathrm{~N}_{27} \mathrm{O}_{16}: \mathrm{C} 39.96$. H 4.13. N 24.20: found: C 39.68. H 4.42. N 24.67.

$X$-Ray crystal structure determination of 7 . Single crystals of 7 suitable for X-ray work were grown by slow craporation. The data collection was perlormed at $223 \mathrm{~K}$ with a Sicmens SMART dillractometer $\left(\mathrm{MoK}_{c k} \lambda=0.71073 \mathrm{~A}\right)$ cquipped with a CCD area detcctor. An cmpirical absorption correction was applicd (SADABS). The structure was solved by dircet methods and refincd initially by full-matrix leastsquares method (SHELXTL). Cry stal data for $7:\left[\left(\mathrm{C}_{36} \mathrm{H}_{3} \mathrm{H}_{12} \mathrm{~N}_{2} \mathrm{O}_{12}\right)\right.$ $\left.\cdot\left(\mathrm{C}_{i} \mathrm{H}_{10} \mathrm{~N}_{2}\right)\right] \cdot 2 \mathrm{Br} \cdot 10 \mathrm{H}_{2} \mathrm{O}, M_{r}=1+47,03$, monoclinic. $P 2 / n, a$ $=11.8935(3)$ A. $b=15.5261$ (4) A. $c=14.8604$ (3) A. $\beta=$ $91.672(1)^{\circ} . V=2742.95(\mathrm{Il}) \mathrm{A}^{3} . Z=2 . \rho_{\text {calcil }}=1.752 \mathrm{gcm}^{-3}$. $\mu=1.59 \mathrm{~cm}^{-1}$. Due to the inversion center located at the center of $\mathrm{CB}[6]$ the guest molecule is disordered over two sites. All the non-hydrogen atoms except for the disordered ones were refined anisotropically. Some water molccules were lound to be disordered: they were refined with suitable disorder models. Final block-diagonal matrix lcast-squares relinement on $l^{*}$ with all 4281 reflections and 412 variables converged to $R I(I>2 \sigma(I))=0.0615 . \omega R 2$ (all data) $=0.1644$. and $\mathrm{GOF}=1 .(081$. Crystallographic data for the structure reported here have becn deposited with the Cambridge Crystallographic Data Contre (Deposition No. CCDC-182491). The data can be obtained frec of charge via http: nu'uecds. camacuk pert catrequatreq.egi (or from the CCDC. 12 Union Road. Cambridge CB2 IEZ. UK: fax: +44 I223 336(133: c-mail: deposil (accdc.cam.ac.uk).

\section{Results and Discussion}

The synthesis of (4-pyridiny lmethyl)aminoalky limino diacctic acids is outlined in Scheme I. Axidoalkyl amines $1^{\circ}$ were dialkylated with methyl bromoacetate to afford the tertiary amines $\mathbf{2}$ in high yields. The azido group in $\mathbf{2}$ was reduced into amine followed by reductive alky lation with 4pyridinecarbosaldehyde and $\mathrm{Cbz}$ protection of the resulting secondary amine to afford Cbz-protected diesters in moderate yields. The $\mathrm{Cbz}$ group was deprotected and the ester group was hydrolyzed simultaneously using $\mathrm{HBr}-\mathrm{H}_{2} \mathrm{O}$ to give (pyridy /methyl)aminoalks liminodiacetic acids 3 .

Threading of $\mathrm{CB}[6]$ with $\mathbf{3 a}$ and $\mathbf{3 b}$ followed by immediate isolation of the product gives [2]pseudorotaxane $4 \mathbf{a}$ and 4 b. respectively (Scheme 2). To our surprise. the $\mathrm{CB}[6]$ bead in 4 resides exclusively at the pyridylmethyl unit as evidenced by ${ }^{1} \mathrm{H}-\mathrm{NMR}$ spectroscopy. ${ }^{4}$ For example, the ${ }^{1} \mathrm{H}-\mathrm{NMR}$ spectrum of 4a (Figure $1 b)$ reveals that the signals $(a, b$. and 


$$
\longrightarrow \text { a: } n=1,97 \% ; b: n=2,98 \%
$$

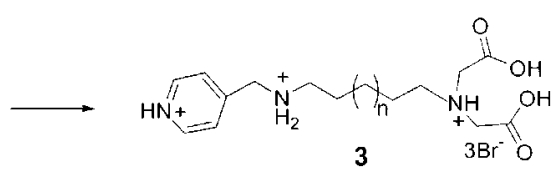

a: $n=1,40 \% ; \mathbf{b}: n=2,38 \%$

Scheme 1. Synthesis of the string 3 .

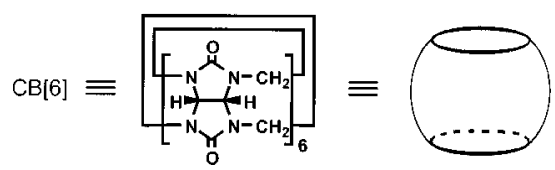

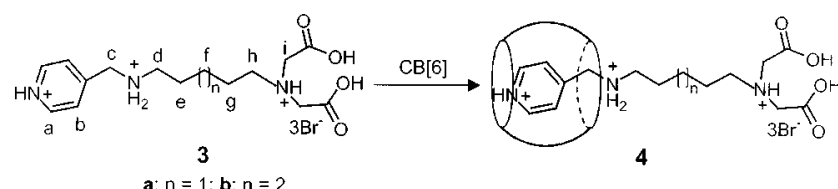
a: $n=1 \cdot b: n=2$

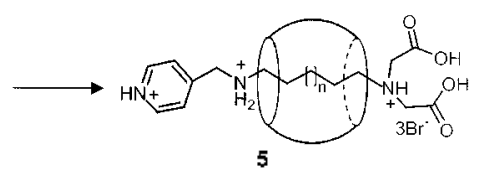

Scheme 2. Threading of $\mathrm{CB}[6]$ with the string 3 to form the kinetic product $\boldsymbol{4}$ and its conversion to the themodrnamic product 5 .

c) for the pyridylmethyl unit in ta are up-licld-shifted relative to those in 3a. For the better understanding of the unexpected result we attempted to grow single crystals of 4 suitable for X-ray crystallography but failed. Therelore. wo decided to investigate the structure of the host-guest complex (7) between $\mathrm{CB}[6]$ and protonated py ridylmethylamine 6, instcad (Scheme 3). In the crystal structure of 7 (Figure 2) the guest molecule resides inside the cavity while disordered over two sites related to cach other by the inversion center located at the center of the cavity. The disorder prevented us from locating the protons attached to nitrogen atoms. but the

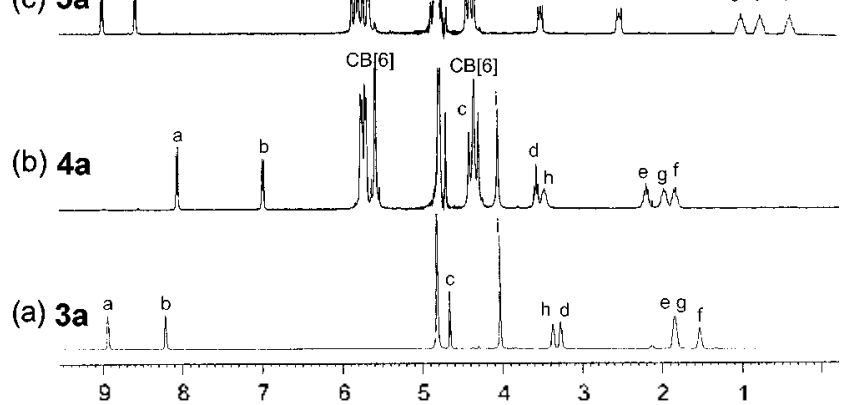

Figure 1. Comparison of the ${ }^{~} \mathrm{H} N \mathrm{NM}$ s s eetra (in $\mathrm{D}_{2} \mathrm{O}$ at $25^{\circ} \mathrm{C}$ ) of 3a (a), $4 \mathbf{a}(\mathrm{b})$, and $5 \mathbf{a}(\mathrm{c})$.

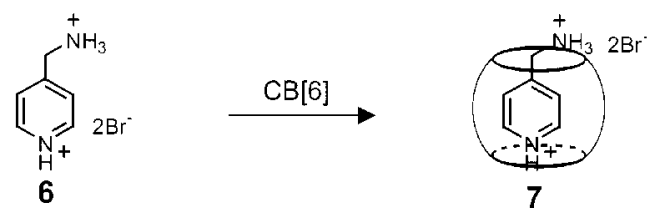

Scheme 3. Host-guest complex 7 lonned belween CB[6] and protonated pyridylmethylamine 6 .

(a)

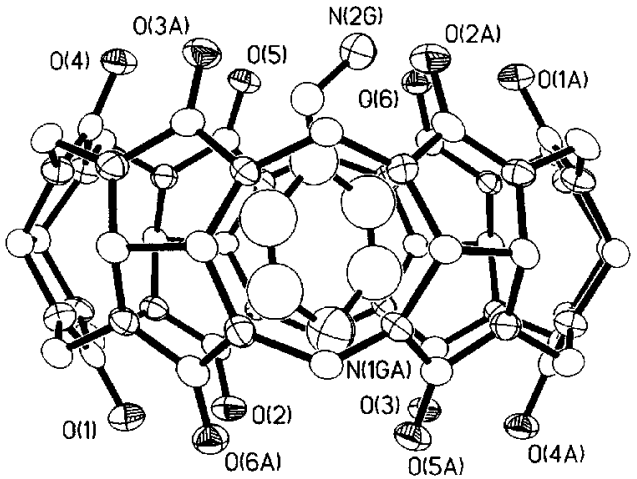

(b)

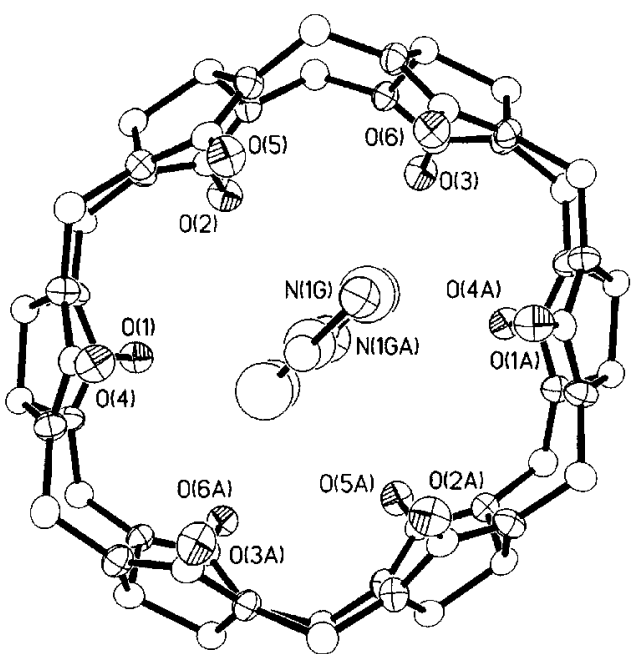

Figure 2. X-ray erystal structure of 7 : (a) side view and (b) top) view. Hydrogen atoms. counter antions $\left(\mathrm{Pr}^{-}\right)$, and solvent $\left(\mathrm{H}_{2} \mathrm{O}\right)$ molecules are omitted for clarily. Hyalrogen bonding inleractions: $\mathrm{N} 2 \mathrm{G} \cdots \mathrm{OlA} 2.79(\mathrm{I}) \AA \mathrm{A}, \mathrm{N} 2 \mathrm{G} \cdots \mathrm{O} 5 \mathrm{5} 3.05(\mathrm{l}) \mathrm{A}, \mathrm{N} 2 \mathrm{G} \cdots \mathrm{O} 62.88(\mathrm{l}) \AA$.

cxistence of two $\mathrm{Br}^{-}$ions in the lattice suggests that both amine and pyridine nitrogen atoms are protonated. The $\mathrm{CB}[6]$ host shows an ellipsoidal distortion to acconmodate the guest molecule (Figure 2b). The major driving force for the inclusion of the guest in $\mathrm{CB}[6]$ appears to be the chargedipole and hydrogen bonding interactions between the protonated amine group of the guest and the portal oxygen atoms as well as the hydrophobic interaction between the aromatic residue of the guest and the inside wall of the host. The charge-dipole interaction between the protonated pyridyl nitrogen atom of the guest and the portal oxygen atoms may also contribute to the stability of the complex. ${ }^{9}$ Some important geometrical parameters showing the hostguest interactions are listed in the caption of Figure 2.

Upon standing in solution ta and th slowly converts to $5 \mathbf{a}$ and $\mathbf{5 b}$, respectively. as evidenced by 'H NMR spectroscopy: 


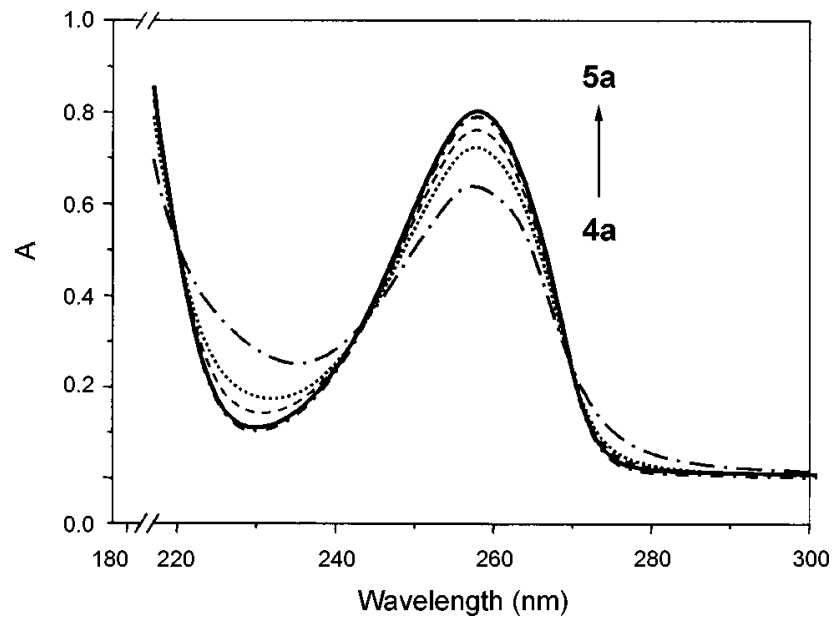

Figure 3. UV-visible spectral changes associated with the conversion ta 10 5a in $\mathrm{I}_{2} \mathrm{O}$ at $25^{\circ} \mathrm{C}$. The absorption spectra tise takm with a $0.23 \mathrm{~m} \mathrm{M}$ solution.

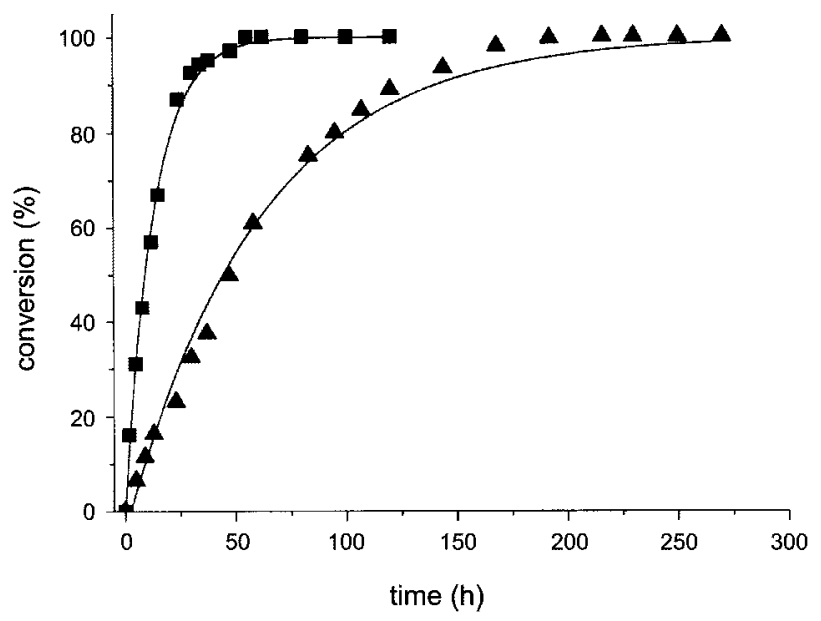

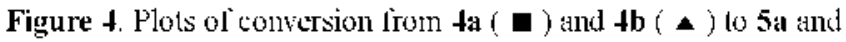
5b. respectively at $25^{\circ} \mathrm{C}$.

The conversion is very slow at room temperature but occurs rapidly and completely in a few minutes at $60-70^{\circ} \mathrm{C}$. The comparison of the ${ }^{1} \mathrm{H}-\mathrm{NMR}$ spectra of $4 \mathbf{a}$ and $\mathbf{5 a}$ (Figure 1) reveals that the signals $(a, b$, and $c)$ for the pyridymethyl unit in 5a are down-field-shifted while those ( $d . e . f$. and $g)$ for the alkyl unit are up-field-shifted relative to those in $\mathbf{4 a}$. In addition, the signal $i$ in 5 a is down-field-shifted relative to that in ta. These observations are consistent with the complete and imeversible novement of the $\mathrm{CB}[6]$ bead from the pyridylmethyl site in ta to the alkyl site in 5a. The conversion is also accompanicd by change in UV-risible spectrum as shown in Figure 3 . $^{\text {li }}$ The intensity of the band at $258 \mathrm{~nm}$ increases upon conversion from ta to 5a. This spectral change must be associated with the morement of $\mathrm{CB}[6]$ from the pyridy'methyl site to the alkyl site but the exact nature of the change is unknown at present time.

The kinetics of the conversion from ta to $5 \mathrm{a}$ and from $\mathbf{4 b}$ to $\mathbf{5 b}$ has been studied at $25^{\circ} \mathrm{C}$ by 'H-NMR spectroscopy.
Figure 4 shows that the conversion follows a lirst order kinetics. The conversion from ta to 5 a occurs laster than that from th to 5 b. The first order rate constants are calculated to be $2.1( \pm 0.1) \times 10^{-5} \mathrm{~s}^{-1}$ and $5.0( \pm 0.3) \times 10^{-6}$ $\mathrm{s}^{-1}$ for the conversion from $+\mathbf{a}$ to $\mathbf{5} \mathbf{a}$ and that from $+\mathrm{b}$ to $\mathbf{5} \mathbf{b}$. respectively. The activation parameter $\Delta C^{\dagger}$ is estimated to be $23.8 \mathrm{kcal} / \mathrm{mol}$ and $24.7 \mathrm{kcal} / \mathrm{mol}$ lor the former and the latter conversion. respectively.

In summary. we synthesized novel [2]rotaxanes by reacting $\mathrm{CB}[6]$ and (4-py ridiny Imethyl)aminoalky limino diacetic acids. In the initial products. the $\mathrm{CB}[6]$ bead is threaded on the terminal pyridiny lmethy lamine unit. Upon standing in solution at room temperature. however the bead translocates slowly but completely to the inner diaminoalkane unit to form thermodynamically more stable [2]rotaxanes. This unexpected result may provide an insight into the synthesis of other rotaxanes containing $\mathrm{CB}[$ (6) by a slipping mechanism. ${ }^{11} \mathrm{Wc}$ are currently working on anchoring the [2]pseudorotaxanes on a surlace by covalent modification.

Acknowledgment. We gratefully acknowledge the Korcan Ministry of Science and Technology (Creative Rescarch Initiative Program) lor support of this work, and the Korcan Ministry of Education (Brain Korca 2l program) for graduate studentships to S.-Y. Kim.

\section{References and Notes}

1. (a) Balzani. V.: Credi. A.: Raymo. F. M.: Stoddart. J. F. ingen:

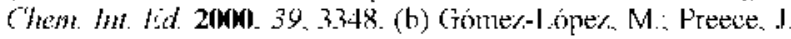
A. Stoddart I. I. Nanoted holog: 1996. 7. I8?.

2. Molecular machines special issues. Ace. (Them. Res. 2001 , 37, 409.

3. Behrend. R.: Meyer. E.: Rusche. F. Justus Liebigs . Am. Chem. 1905. 339. 1. New cucurbituril homologues $\mathrm{CB}[5]$. $\mathrm{CB}[7]$ and CB[8]. which are pentameric. heptameric. and octamerie species. respectively. have been recently reported: Kim. I. Iung. I.S.:

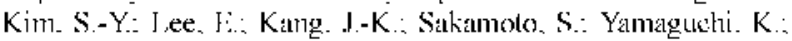
Kim. K.J.Am. Chem. Soc. 2000. 122,540.

4. (a) Mock. W. L. In Comprehensive Supromoleculor Chemisty: Vogtle. F.. Ed.: Pergamon: Oxford. 1996: Vol 2. p 477. (b) Mock. W. L.: Shih. N.-Y. J. Org Chem. 1986. 57 . 4446 .

5. Kim. K. (7hem. Soc. Rev 2012.31.96.

6. (a) Jum. S. I: I ee. J. W: Sakamolo. S.: Yamaguchi. K.: Kim. K. Tetrahedron Lett. 2000, 11, 47I. (b) I ee. I. W. Kim. K.: Kim. K. CHem. Conmmin. 2001. 1042.

7. Chia. S.: Cao. J.: Stoddart. I. F.: Zink. J. I. Angen. (7hem. In. Ed. 2001.40 .2447$.

8. I.e. I. W. Jun. S. I.: Kim. K. Fetratedom lent 2001 42. 2709.

9. We thitrk that the nature of the interaction between the protonated mitrogen atom of the guest and portal oxygen aloms is chargedipole interaction rather than lydrogen bonding considering the geometric requirements for the latter intcraction.

10. (a) Hoffmanm. R.: Knochc. W.: Fcmin. C. . Chem. Soc. laraday Troms. 1994. 90. 15(K. (b) Neugebauer. R.: Knoche. W. . Chem Soc. Perkin Truts. 2 1998. 529.

11. (a) Amabilito, 1). 13: Ashton. P. R.: Belohradiky. M: Raymo. I. M.: Stoddart. J. F. J. Chem. Soc., Chem Conmm 1995. 747. (b) Raymo. F. M.: Houk. K. N.: Stoddart. J. F. $J$. Am ( $/ \mathrm{km}$ Soc: 1998. 120.9318. 